\title{
SEVILLA Y LA LITERATURA
}

\author{
Enrique Baltanás \\ Universidad de Sevilla
}

La costumbre de homenajear a un catedrático mediante un volumen colectivo en que se reúnen colaboraciones de colegas, discípulos y amigos se inició en España con el que en 1899 (Madrid, Victoriano Suárez) se tributó a don Marcelino Menéndez Pelayo al cumplirse el vigésimo año de su profesorado. Desde entonces acá, mucho es lo que ha llovido - el calendario ha pasado ya las páginas de dos siglos - pero la costumbre se ha demostrado no sólo como la mejor para agradecer y agasajar, sino también, lo que es más importante aún, como inmejorable ocasión para profundizar en los temas y problemas que la obra del maestro homenajeado nos propone y suscita. Buen ejemplo de ello es la obra que reseñamos, Sevilla y la literatura ${ }^{l}$, volumen homenaje a quien fuera durante tantos años profesor de la Hispalense, y siempre de una manera u otra a ella vinculado -últimamente, desde 1989, como Doctor honoris causa-, don Francisco López Estrada. El tema expresado en el título - Sevilla y la literatura, en el más amplio abanico de sus relaciones - es el hilo conductor que agavilla y unifica los trabajos en él recogidos.

Como explican en su Prólogo los editores, el volumen representa la traslación a letra impresa de un homenaje entrañable, que se desarrolló a través de un ciclo de cuatro conferencias - la última de las cuales la pronunció el propio López Estrada-, para dar así la posibilidad de participar en el mismo tanto a los alumnos de la Facultad de Filología como a diversas personas que, en un momento u otro, estuvieron muy cerca de don Francisco en su etapa sevillana. De este modo, pues, el interés científico del libro no se presenta solo ni ex abrupto, sino como culminación de una actividad docente y de unas muy humanas - y universitarias - vivencias. De ahí también que la participación se haya circunscrito intencionadamente, en el aspecto académico, a los profesores de Literatura Española de la Facultad de Filología, lo que explica las, si así no fuera, numerosísimas ausencias, nacionales y extranjeras, que podrían notarse tratándose de un homenaje a don Francisco.

Han dispuesto los editores el volumen - a nuestro juicio, acertadamente - en tres partes claramente diferenciadas. En la primera de ellas se atiende al perfil académico, literario y humano del homenajeado. Jesús Díaz García —a quien, como Decano de la Facultad, correspondió presentar el homenaje-, Pedro M. Piñero, Joaquín Caro Romero, Rafael de Cózar, Aquilino Duque, María de los Reyes Fuentes, Julia Uceda y Rogelio

\footnotetext{
${ }^{1}$ Rogelio Reyes Cano, Mercedes de los Reyes Peña y Klaus Wagner (eds.), Sevilla y la literatura. Homenaje al Profesor Francisco López Estrada en su 80 cumpleaños, Sevilla, Universidad de Sevilla, 2001.
} 
Reyes Cano trazan de mano maestra no sólo la trayectoria investigadora, universitaria y cultural del homenajeado, sino que en sus semblanzas y recuerdos nos aportan una impagable visión de una época y de una ciudad - acaso de una ciudad en una época determinada - que, a trueque de sus sombras, e incluso tinieblas, reales o imaginarias, nos puede hoy llevar a pensar quizás, con Manrique, que "todo tiempo, pasado, (y ojo a las comas) fue mejor." En todo caso, y salvado lo que en ello pueda haber de concesión a la nostalgia (nada plañidera: abundan los toques de humor), los colaboradores de esta primera sección nos ofrecen un cuadro de una Universidad aún no masificada y en la que todavía la vocación docente se desbordaba con creces de los estrictos horarios funcionariales para derramarse en un quehacer cultural sostenido y constante, que hoy puede sorprendernos. No debe pasarse por alto, pues, el valor histórico y documental de estas páginas, sin olvidar el propiamente literario.

Culmina esta primera sección la "Bibliografía" (2000 inclusive, y completada con útiles índices de autores, obras y asuntos) de don Francisco López Estrada: nos quedaremos sorprendidos no sólo por su cantidad, sino por la variedad y coherencia de sus intereses. Además de sus trabajos clásicos y de sobra conocidos, no hace falta citarlos, la curiosidad del lector podrá espigar pequeñas joyas de erudición y crítica, dispersas, pero no perdidas, en esta opera omnia bibliográfica, magnífica visión de conjunto de toda una vida consagrada a la investigación y la docencia.

Las cuatro conferencias impartidas, y que ahora se publican, son las de Maxime Chevalier ("Anécdota y cuento en la Sevilla áurea"), Pedro M. Piñero ("La configuración poética de la versión vulgata de Don Bueso"), Mercedes de los Reyes Peña ("Un pasquín anti-inmaculista en la Sevilla del primer tercio del siglo XVII") y el propio Francisco López Estrada ("Tomás Moro y Sevilla"), todas ellas ofrecidas en 1999, en el curso del homenaje ya mencionado.

La última sección del libro, bajo el epígrafe general de "Colaboraciones", se ordena cronológicamente en dos apartados: "Siglo de Oro" y "Siglos XVIII-XX". Al primero de ellos contribuyen Manuel Abad ("Un disfrazado de mujer en una comedia del sevillano Monroy"), Manuel Bernal Rodríguez ("Noticia de los juegos y fiestas de toros en la Sevilla del Quinientos"), Mercedes Cobos ("Francisco de Calatayud y Sandoval no nació en Sevilla. Noticias sobre su ascendencia"), Jacobo Cortines Torres ("Las patrias de Don Juan"), Aurora Domínguez Guzmán ("Relaciones de fiestas inmaculistas en Sevilla, 16151617. Catálogo descriptivo"), Francisco Javier Escobar Borrego ("La perviencia del himno pagano en la poesía de Fernando de Herrera"), Begoña López Bueno ("Una epístola (moral) de Fernando de Soria: canon genérico y contexto sevillano"), Francisco Márquez Villanueva ("Crear en Sevilla: el caso de Fernando de Herrera"), Juan Montero ("Problemas textuales en la Sátira del Licenciado Pacheco. Primera entrega"), José Antonio Muñoz Rojas ("Del libro inédito El Comendador") y Klaus Wagner ("Apuntes para la historia de la difusión del libro sevillano en la primera mitad del siglo XVI"). Sobre los siglos XVIII al XX aportan sus trabajos María José Alonso Seoane ("Sevilla en las revistas románticas. La colaboración del Conde de Campo Alange en El Artista"), José María Barrera López ("Gran Guignol (1920): una revista olvidada de la vanguardia sevillana en el centenario de Borges"), Piedad Bolaños Donoso ("El Duque de Rivas y su tragedia Ataúlfo. Contribución al estudio de la censura teatral sevillana en el siglo XIX"), Miguel Cruz 
Giráldez ("La poesía de María de los Reyes Fuentes") y Marta Palenque ("Sevilla en el recuerdo: datos para la biografía de Rafael Cansinos Assens (1915-1920)").

Hay que destacar, por último, el esmero y pulcritud con que los editores han cuidado del volumen, hasta en sus menores detalles tipográficos, lo que hace del mismo un modelo de equilibrio y armonía entre las Humanidades y lo humano, el contenido científico valioso y el soporte material digno, la mirada hacia atrás y la continuidad hacia el futuro que representan las investigaciones aquí recogidas sobre nuestras letras de quienes fueron, algo más que alumnos, discípulos, y que se enorgullecen, sin complejos, de serlo. 